\title{
Paclitaxel Weekly Regimen
}

National Cancer Institute

\section{Source}

National Cancer Institute. Paclitaxel Weekly Regimen. NCI Thesaurus. Code C160103.

A chemotherapy regimen consisting of weekly paclitaxel that may be used in the treatment of breast, cervical, ovarian, fallopian tube, and primary peritoneal cancers. 